\title{
COMPARING THE EFFECTIVENESS OF ASSAY FORMULATION FROM VARIOUS TRADITIONAL PLANTS AS PEDICULICIDE AGAINST Pediculus humanus capitis
}

\author{
Desy Rosalina Sari ${ }^{\left.i^{*}\right)}$, Iman Surya Pratama ${ }^{1}$, Galuh Tresnani ${ }^{2}$ \\ ${ }^{1}$ Pharmacy Programme, Faculty of Medicine, Mataram University, Majapahit Street \\ No. 62, Mataram 83115, Indonesia \\ ${ }^{2}$ Biology Programme, Faculty of Mathematics and Natural Sciences, Mataram University, \\ Majapahit Street No. 62, Mataram 83115, Indonesia
}

Received September 12, 2019; Accepted December 15, 2020

\begin{abstract}
Pediculosis capitis is an infection with a fairly high incidence in children. Plants that contain eugenol, as frangipani (Michelia champaca L.), ceylon ironwood (Mesua ferrea L.), cinnamon (Cinnamomum burmannii), and sugar apple (Annona squamosa L.) have potential as an alternative pediculicide. This study aimed to compare the effect of traditional formulation of each plant with in vitro assay. The effectiveness of in vitro pediculicide was assessed from the postimmersion mortality time of the traditional formulation, permethrin $1 \%$ as the positive control and coconut oil as the negative control. The mechanism was observed using histopathological observation. The percentage of mortality time of lice was analyzed using One-Way ANOVA of SPSS 16. Histopathological aspects and infestation decrease were presented descriptively. This study took place for about 3 months and was conducted in Mataram University, West Nusa Tenggara. The results showed that frangipani leaves had the optimum pediculicide effect because the highest efficacy demonstrated by frangipani leaves formulation revealed the effect lower than permethrin 1\% (LT: 350 minutes). In observation of histopathology, frangipani leaves formulation indicated the presence of anoxia similar to permethrin $1 \%$.
\end{abstract}

Keywords: histopathology; in vitro; natural product; pediculicide; permethrin.

\section{INTRODUCTION}

Pediculosis capitis or infection of the scalp by Pediculus humanus capitis is a global health problem that often occurs in children (Combescot-Lang et al., 2015). Pediculosis cases have increased in the past three decades, but pediculosis is still categorized as a neglected disease (Doroodgar et al., 2014; Feldmeier and Heukelbach., 2009). The prevalence of pediculosis in Indonesia is not known for certain. Data in 2002-2009 show the percentage of patients with pediculosis is 20\% (Kementerian Kesehatan RI, 2010).

Heavy infestation of pediculosis can cause itching, rash, urticaria, swelling of the lymph nodes, scars, and sleep disruption (Burgess, 2009; Mehlhorn and Mehlhorn, 2009; Mumcuoglu et al., 2009). In addition, pediculosis also leads to psychological problems such as feeling alienated as a result of being considered to have a dirty lifestyle.

Lice comb and conventional medicine are commonly used, but have some problems. The use of permethrin and lindane group has been reported to cause long-term resistance and toxicity of the central nervous system, while carbaryl is potentially carcinogenic (Rassami and Soonwera, 2011).

Natural ingredients are known to have milder side effects and contain a variety of metabolites that have a synergistic effect. 
Studies on essential oil of clove, eucalyptus and anise show pediculicide activity similar to malathion and ovicidal activity better than malathion (Yoon et al., 2014). Additionally, natural ingredients tend to have smaller toxicity and are more ecologically friendly than conventional drugs (Mehlhorn and Mehlhorn, 2009; Soonwera, 2014).

Eugenol is one of essential oils known to have pediculicide effects. A high content of eugenol in clove oil and bandotan (Ageratum conyzoides) hydro alcoholic extracts $20 \%$ shows pediculicide activity $>90 \%$ (Candy et al., 2017; Shailajan et al., 2013). Frangipani (Michelia champaca L.), cinnamon (Cinnamomum burmannii), and ceylon ironwood (Mesua ferrea L.) are plants that contain eugenol, but testing of the plant activity as pediculicide agents is still limited. This prompts further research to compare the pediculicide effects of each of these plants based on the mortality time of in vitro assay and histopathological observation.

\section{METHODS}

\section{Sample test preparation}

Pediculus humanus capitis used as the sample test was collected from 6-12 years old probands from elementary school 1 North Gerung, West Lombok, with their agreement in the form of informed consent. The respected probands were not treated with conventional drugs at least one month before (Carpinella et al., 2007).

The sample test was collected with a lice comb through the probands scalp. After that, lice were collected along the hair strands of probands. Subsequent sample test was identified in the Laboratory of Biology, Faculty of Mathematics and Natural Sciences, Mataram University. Head lice were protected from the heat and in vitro assays started within 2 hours after sample test collection (Candy et al., 2017).

\section{Formula Preparations}

Leaves of frangipani (Michelia champaca L.), cinnamon (Cinnamomum burmannii), ceylon ironwood (Mesua ferrea
L.), and sugar apple (Annona squamosa L.) were obtained from Pringgarata, Central Lombok and Lingsar, West Lombok, West Nusa Tenggara. Plant determination was conducted in Herbarium Bandungense, School of Life Sciences and Technology, Bandung Institute of Technology. The leaves of each plant were washed with water, then drained, chopped, dried, and stored in a sealed container.

The formula was made by grinding each plant leaf along with coconut oil as a carrier liquid. The mixture was further squeezed, filtered and stored in a tightly closed container.

\section{Determining effects of pediculicide formula in vitro}

The test began with the preparation of a formula in a concentration of $20 \%$ (Heukelbach et al., 2007). The formula was distributed evenly on the filter paper with a diameter of 5 $\mathrm{cm}$, which was placed inside a $5 \mathrm{~cm}$ petri dish. After 5 minutes when the liquid had spread, filter paper was dried until the solution did not drip.

Thereafter, the filter paper was placed into clean petri dishes and ten lice were placed on each filter paper. Observations in all treatment groups were performed to see the difference every 10 minutes until all lice in each treatment group experienced a mortality effect. After that, the average mortality time of each treatment group was compared.

\section{Histopathologic test}

In histopathology observation, the sample from each treatment group was placed in a vial and fixed with $70 \%$ alcohol for two days. Results of subsequent fixation were clarified with $\mathrm{KOH}$ for 24 hours. Having been cleared up, the samples were dehydrated in graded concentrations of alcohol, and then soaked in clove oil and rarefied back in xylol. In the last stage, the sample was placed on a glass object, dropped a wax, and given a glass cover. The preparation slide was observed under a microscope. The parts that are observed are dark spiracles or blood stains on the whole mount (Cestari et al., 2004). 


\section{Data analysis}

In vitro test data analysis was performed using one-way ANOVA with SPSS software. Results with $\mathrm{p}<0.05$ were considered statistically significant. Lice which are exposed to the extract showing no evidence of efficacy in 180 minutes are considered to have KT50 >180 minutes (Yones et al., 2016). Histopathology data analysis was done descriptively.

\section{RESULTS AND DISCUSSION}

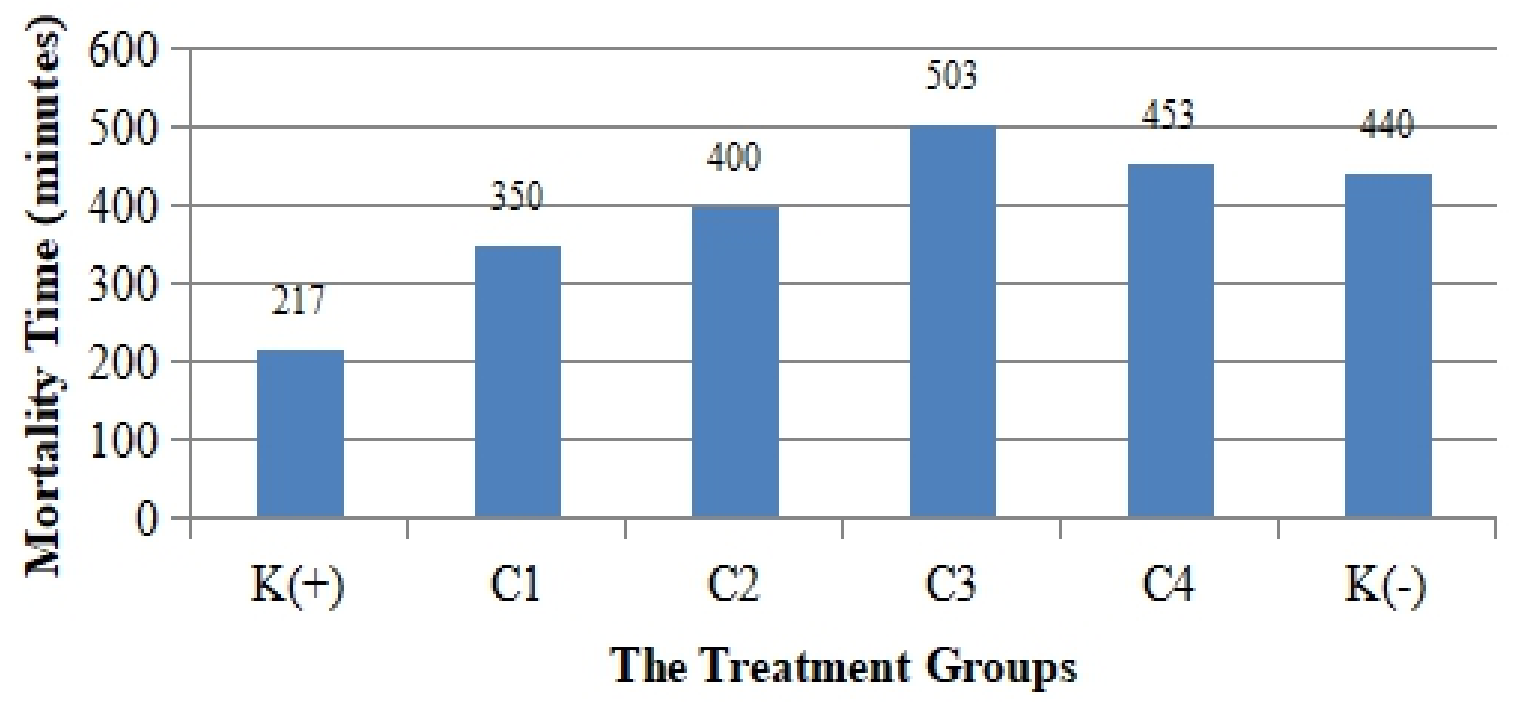

Figure 1. The difference in the onset of each treatment

$\mathrm{K}(+)=$ Positive control (Permethrin 1\%); $\mathrm{C} 1 \quad$ formulation; $\mathrm{C} 4=$ Sugar apple leaves $=$ Frangipani leaves traditional formulation; traditional formulation; $\mathrm{K}(-)=$ Negative $\mathrm{C} 2$ = Cinnamon leaves traditional formulation; control (coconut oil).

$\mathrm{C} 3$ = Ceylon ironwood leaves traditional
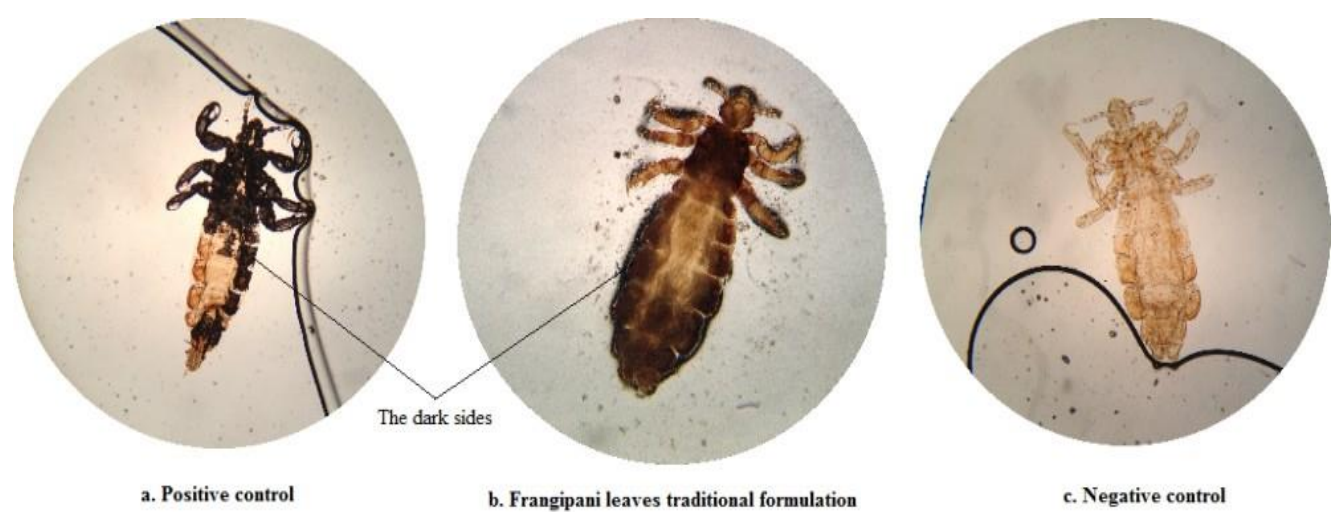

Figure 2. Histology after each treatment of the positive control group (permethrin 1\%), frangipani leaves traditional formulation, and negative control (coconut oil) (the photo is personal documentation) 
Pediculicide activity of the traditional formulation from various plants against Pediculus humanus capitis with in vitro test showed a mortality effect. The results show there are differences in the onset of lice mortality in each treatment group. Mortality is defined as a state of the disappearance of all signs of life in permanent (World Health Organization, 2012).

Based on Figure 1, it can be seen that the positive control group (permethrin 1\%) has the most rapid mortality effect compared to other treatment groups. The slowest mortality effect is seen in the group of ceylon ironwood leaves traditional formulation.

Statistics show that there is a significant difference in the data of all groups, except in the $\mathrm{C} 4$ group (sugar apple leaves traditional formulation) against the $\mathrm{K}(-)$ group (coconut oil). C4 group has no pediculicide effect because there is no significantly different data to $\mathrm{K}(-)$ group. C3 group also has no pediculicide effect because the LT is bigger than K (-) group. Empirically, the sugar apple has been used as a pediculicide. A previous study shows that the efficacy of sugar apple seed can give 90\% effect (Intaranongpai et al., 2006). This study suggests that the pediculicide effect of sugar apple leaf traditional formulation can be said lower than the empirical use.

C1 group (frangipani leaves traditional formulation) and $\mathrm{C} 2$ (cinnamon leaves traditional formulation) have a significant difference against $\mathrm{K}(+)$ (permethrin 1\%). Thus, the two formulas have pediculicide effect comparable with $\mathrm{K}(+)$. However, based on the average mortality time on a graph, it is known that the $\mathrm{C} 1$ group has the shortest mortality time. Based on these results, we can conclude that the most pediculicide effect is demonstrated by the $\mathrm{C} 1$ group.

Frangipani is known to contain eugenol and linalool that in previous studies are said to have an effect as pediculicide (Candy et al., 2017; Shailajan et al., 2013). Linalool compound is known as one of the largest components of frangipani, while eugenol is not included as a major compound (Rout et al., 2011). The synergic effect of the two compounds is suspected as the cause of high effect from frangipani leaves traditional formulation (Dhumal and Waghmare, 2015). Eugenol and methyl salicylate from clove bud oil are claimed to have fumigant activity against eggs and females of $P$. humanus capitis. The mode of delivery of the oils is likely by vapor action via the respiratory system. The insecticidal mode of action may be related to the specific neurotoxic action such as the octopaminergic action (Yang et al., 2003; Yang et al., 2004).

Based on the histopathological picture of head lice in the positive control, it can be seen that permethrin works by attacking the respiratory tract (spiracles) in the abdomen of lice's head. The permethrin target-voltage sensitive sodium channel (VSSCs) in the nervous system causes depolarization of nerve and muscle hyperexcitability followed by paralysis and mortality (Yoon et al., 2014; Clark et al., 2013). Muscle paralysis causes the respiratory tract to become stiff. When the respiratory tract is closed, the inside liquid will be stuck and there will be no air supply from outside of the body. This can result in an anoxic environment which can be a major cause of death. This is indicated by the dark part and thoracic spiracles (Figure 2).

The outer portion of the respiratory tract can also be closed preventing water excretion, which can lead to rupture of the intestine. It is characterized by the presence of blood stains on the filter paper of positive control group.

On the negative control, the thoracic spiracles section looks clear. Muscle contraction and movement of internal organs can cause the water to move through the trachea, thus carries oxygen to the tissues infestation. This causes the absence of the dark on the results of histology (Figure 2).

\section{CONCLUSION}

Traditional formulation of frangipani leaves has the best pediculicide effect compared to other traditional formulation with slower effect than the positive control. Based on in vitro studies, frangipani leaves traditional formulation has the fastest 
mortality time at $100 \%$ lice mortality. Frangipani leaves traditional formulation mechanism is similar to the positive control which is reviewed in histopathological manner.

\section{ACKNOWLEDGMENT}

I am deeply indebted to my supervisor and Mataram University for the support and thoughtful guidance.

\section{REFERENCE}

Burgess, I.F., 2009. Current Treatments for Pediculosis Capitis. Curr. Opinin. Infect. Dis., (22)2, 131-136.

Candy, K., Nicolas, P., Andriantsoanirina, V., Izri, A., and Durand, R., 2017. In Vitro Efficacy of Five Essential Oils Against Pediculus humanus capitis. Parasitol. Res., (117)2, 603-609.

Carpinella, M.C., Miranda, M., Almiron, W.R., Ferrayoli, C.G., Almeida, F.L., and Palacios, S.M., 2007. In Vitro Pediculicidal and Ovicidal Activity of An Extract and Oil from Fruits of Melia azedarach L. J. Am. Acad. Dermatol., (56) 2, 250-256.

Cestari, I.M., Sarti, S.J., Waib, C.M., and Branco Jr, A.C., 2004. Evaluation of The Potential Insecticide Activity of Tagetes minuta (Asteraceae) Essential Oil Against the Head Lice Pediculus humanus capitis (Phthiraptera: Pediculidae). Neotrop. Entomol., (33)6, 805-807.

Clark, J.M., Yoon, K.S., Lee, S.H., and Pittendrigh, B.R., 2013. Human Lice: Past, Present and Future Control. Pectic. Biochem. Physiol., (106)3, 162-171.

Combescot-Lang, C., Stichele, R.H.V., Toubate, B., Veirron, E., and Mumcuoglu, K.Y., 2015. Ex Vivo Effectiveness of French Over-theCounter Products Against Head Lice (Pediculus humanus capitis De Geer, 1778). Parasitol. Res., (114)5, 17791792.

Dhumal, T.D. and Waghmare, J.S., 2015. A Pediculicidal Activity of Clove Oil. IJPSR., (6)2, 857-865.
Doroodgar, A., Sadr, F., Doroodgar, M., Doroodgar, M., and Sayyah, M., 2014. Examining The Prevalence Rate of Pediculus capitis Infestation According to Sex and Social Factors in Primary School Children. Asian Pac. J. Trop. Dis., (4)1, 25-29.

Feldmeier, H. and Heukelbach, J., 2009. Epidermal Skin Disease: A Neglected Category of Poverty-Associated Plagues. Bull. World Health Organ., (87)2, 152159.

Heukelbach, J., Canyon, D., and Speare, R., 2007. The Effect of Natural Products on Head Lice: In Vitro Tests and Clinical Evidence. J. Pediat. Inf. Dis., (2)2, 6776.

Intaranongpai, J., Chavasiri, W., and Gritsanapan, W., 2006. Anti-Head Lice Effect of Annona squamosa Seeds. Southeast Asian J. Trop. Med. Public Health, (37)3, 532-535.

Kementerian Kesehatan RI, 2010. Profil Kesehatan Indonesia 2009. Kementerian Kesehatan Republik Indonesia, Jakarta.

Mehlhorn, B. and Mehlhorn, H., 2009. Louse Alarm. Düsseldorf University Press.

Mumcuoglu, K.Y., Gilead, L., and Ingber, A., 2009. New Insights in Pediculosis and Scabies. Expert Rev. Dermatol., (4)3, 285-302.

Rassami, W. and Soonwera, M., 2011. Effect of Herbal Shampoo from Long Pepper Fruit Extract to Control Human Head Louse of The Ladkrabang Childrens, Bangkok, Thailand. J. Agri. Tech., (7)2, 331-338.

Rout, P.K., Naik, S.N., and Rao, Y.R., 2011. Composition of The Concrete, Absolute, Headspace and Essential Oil of The Flowers of Michelia champaca Linn. Flavour Fragr. J., (21)6, 906-911.

Shailajan, S., Wadke, P., Joshi, H., and Tiwari. B., 2013. Evaluation of Quality and Efficacy of An Ethnomedicinal Plant Ageratum conyzoides L. in The Management of Pediculosis. J. Young Pharm., (5)4, 139-143.

Soonwera, M., 2014. Efficacy of Herbal Shampoo Base on Native Plant Against 
Head Lice (Pediculus humanus capitis De Geer, Pediculidae: Phthiraptera) In Vitro and In Vivo in Thailand. Parasitol. Res., (113)9, 3241-3250.

World Health Organization, 2012. Strengthening Civil Registration and Vital Statistics for Births, Deaths and Causes of Death: Resource Kit. World Health Organization, Luxembourg.

Yang, Y.C., Lee, S.H., Lee, W.J., Choi, D.H., and Ahn, Y.J., 2003. Ovicidal and Adulticidal Effects of Eugenia caryophyllata Bud and Leaf Oil Compounds on Pediculus capitis. J. Agric. Food Chem., (51)17, 4884-4888.

Yang, Y.C., Lee, H.S., Clark, J.M., and Ahn, Y.J., 2004. Insecticidal Activity of Plant Essential Oils Against Pediculus humanus capitis (Anoplura: Pediculidae). J. Med. Entomol., (41)4, 699-704.
Yones, D.A., Bakir, H.Y., and Bayoumi, S.A.L., 2016. Chemical Composition and Efficacy of Some Selected Plant Oils Against Pediculus humanus capitis In Vitro. Parasitol. Res., (115)8, 32093218.

Yoon, K.S., Previte, D.J., Hodgdon, H.E., Poole, B.C., Kwon, D.H., Abo El-Ghar, G.E., Lee, S.H., and Clark, J.M., 2014. Knockdown Resistance Allele Frequencies in North American Head Louse (Anoplura: Pediculidae) Populations. J. Med. Entomol., (51)2, 450-457. 